\title{
BMJ Open HPV knowledge, burden and genital wart location among heterosexually identified versus homosexually identified men who have sex with men in Lima, Peru: cross-sectional results from a cohort study
}

\author{
Jerome T Galea, ${ }^{1,2,3}$ Segundo R León, ${ }^{2}$ Jesús Peinado, ${ }^{2}$ Gino Calvo, ${ }^{3}$ \\ Jonathan Zamora, ${ }^{3}$ Hugo Sánchez, ${ }^{3}$ Brandon J Brown ${ }^{4}$
}

To cite: Galea JT, León SR, Peinado J, et al. HPV knowledge, burden and genital wart location among heterosexually identified versus homosexually identified men who have sex with men in Lima, Peru: cross-sectional results from a cohort study. BMJ Open 2017;7:e017338. doi:10.1136/ bmjopen-2017-017338

- Prepublication history for this paper is available online. To view these files please visit the journal online (http://dx.doi. org/10.1136/bmjopen-2017017338).

Received 20 April 2017 Revised 18 September 2017 Accepted 19 September 2017

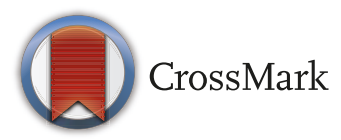

${ }^{1}$ Department of Global Health and Social Medicine, Harvard Medical School, Boston, Massachusetts, USA ${ }^{2}$ Department of Research, Socios En Salud, Lima, Peru ${ }^{3}$ Department of Research, Epicentro Salud, Lima, Peru ${ }^{4}$ Department of Social Medicine and Population Health, Center for Healthy Communities, School of Medicine, University of California, Riverside, California, USA

Correspondence to Dr Jerome T Galea; jerome_galea@hms.harvard.edu

\section{ABSTRACT}

Objectives The relationship between sexual practices, identity and role among Latino men who have sex with men (MSM) and HIV risk is the subject of ongoing investigation but less is known about how these aspects of sexuality relate to human papilloma-virus (HPV), an independent risk factor for HIV. This observational study investigated the relationship between HPV and sexual practices, identity and role as well as other sexually transmitted infection (STI)/HIV risk factors among HIVnegative heterosexually and homosexually identified Peruvian MSM.

Setting Community-based clinic for MSM in Lima, Peru. Participants 756 subjects were screened based on inclusion criteria of: born anatomically male; age $\geq 18$ years; had any anal intercourse with a man during the previous 12 months; residing in metropolitan Lima; HIV negative; willing to commit to twice-yearly clinic visits for 24 months; had not participated in an HIV or HPV vaccine study. 600/756 participants met the inclusion criteria and were enrolled, of whom $48 \%$ (284) identified as homosexual and $10 \%(57)$ as heterosexual, the basis of the analyses performed.

Results Compared with homosexually identified MSM, heterosexually identified MSM had completed fewer years of formal education and were less likely to have: anogenital HPV or visible anal warts; given oral sex to a man; or used a condom with their most recent female sexual partner (all $p<0.05$ ). Conversely, heterosexually identified MSM were more likely to have: visible penile warts; used a condom during last anal intercourse; smoked cigarettes; had transactional sex; and used drugs during sex in the previous month (all $p<0.01$ ). There was no difference found between heterosexually and homosexually identified MSM by syphilis or high-risk HPV prevalence.

Conclusions HPV burden, wart type (penile vs anal) and select HIV/STI risk behaviours differed between heterosexually and homosexually identified Peruvian MSM. Understanding the implications of these differences can lead to tailored HIV/STI prevention interventions for heterosexually identified MSM.

\section{Strengths and limitations of this study}

- This is the first study to examine sexual identity as it relates to human papillomavirus.

- Data collection included both subjective (knowledge, behavioural) measures and objective (DNA, physical exam) measures.

- Due to non-random sampling and a cross-sectional design, causality cannot be established.

- The small sample size precluded more advanced statistical procedures.

Trial registration number NCT01387412.

\section{INTRODUCTION}

Understanding the relationship between reported anal sex practices (ie, insertive only, receptive only, or insertive and receptive) and HIV transmission among Latino men who have sex with men (MSM) can help predict and prevent new infections. ${ }^{1-4}$ Increasingly, however, research has expanded to include sexual practices and Latino MSM's sexual identities (ie, homosexual, bisexual or heterosexual) and roles (ie, activo, pasivo or moderno/versatil) to better understand HIV transmission dynamics in this population. ${ }^{56}$ Sexual identity refers to one's self-identification as homosexual, bisexual or heterosexual while sexual role (activo, pasivo or moderno/ versatil) is a self-identifier that maps onto traditional, gender-based norms used to conceptualise sexual relationships between Latino MSM. ${ }^{78}$ But while the HIV prevention field is adopting a more complex view of Latino MSM sexuality, less is known about how Latino MSM's sexual practices, identity 
and roles relate to other sexually transmitted infections (STI).

The presence of STIs in MSM, particularly ulcerative diseases such as syphilis and the herpes simplex-2 virus but also anal warts (caused by human papillomavirus or HPV), is independently associated with HIV infection. ${ }^{9-13}$ HPV is unique among STIs, however, in two important ways. First, it is the most common STI worldwide (an estimated 630 million people are infected globally ${ }^{14}$ ) and disproportionally affects MSM, with prevalences estimated at $61 \%$ in HIV-negative MSM and 93\% in HIV-positive MSM $^{15}$ compared with $\leq 50 \%$ in men who have sex exclusively with women. ${ }^{16}$ Second, HPV is the only STI for which a safe and effective vaccine that can prevent both anogenital warts and many of the associated cancers exists. ${ }^{17}$ Yet, even in the USA, where the HPV vaccine is recommended for MSM up to age 26, uptake lags far behind other populations for whom it is indicated. ${ }^{18}$

One contributing factor for low HPV vaccination rates among MSM is that vaccination uptake is greatly mediated by medical provider recommendation ${ }^{19}$ and is more likely when men disclose being gay or bisexual to their doctor. ${ }^{18}$ But MSM, particularly those identifying as heterosexual, may be reluctant to share information about sex with other men with medical providers, fearing stigmatisation and discrimination. ${ }^{20}{ }^{21}$ For example, in a qualitative analysis of HPV knowledge, attitudes and treatment experiences among Peruvian MSM, an emergent theme specifically among participants self-identifying as 'not gay' was that genital warts were associated with 'having AIDS' or 'being gay'. ${ }^{22}$

HPV vaccination in Peru presently remains indicated only for adolescent girls, ${ }^{23}$ and while all boys would ideally be offered vaccination as well, MSM-especially the young or sexually naïve-could also benefit. One study of 105 MSM from an inner-city STI clinic in Lima found that $77.1 \%$ were infected with anogenital HPV and $43 \%$ were infected with a carcinogenic type; high-risk HPV type infection was associated with sex work, HIV status and rectal chlamydial or gonorrhoeal infection. ${ }^{24}$ Another study of HPV prevalence among 200 Peruvian MSM found the seroprevalence of HPV types 6/11/16/18-for which the quadrivalent HPV vaccine confers protectionwas $64.3 \%$ and $93.8 \%$ for HIV-negative and HIV-positive MSM, respectively. ${ }^{25}$ While both studies included information related to sexual practices, identity and roles, the analyses conducted do not allow side-by-side comparisons of these factors and HPV, information which could inform HPV surveillance, prevention and treatment for Latino MSM.

In the present study, we aimed to extend the understanding of HPV in Latino MSM by examining sexual identity and role as they relate to HPV prevalence, knowledge, burden and genital wart location, and other STI and HIV risk factors. Since heterosexually self-identified MSM face unique challenges for HIV/STI prevention and treatment compared with other MSM, we focused specifically on this population (ie, excluding transgender women and MSM who self-identified as bisexual) as compared with homosexually identified MSM.

\section{METHODS}

We conducted a cross-sectional analysis of data collected at the baseline visit from a cohort study investigating the role of anogenital warts on HIV acquisition among a convenience sample of 600 HIV-uninfected MSM and transgender women in Lima, Peru (described in detail elsewhere ${ }^{26}$ ). Briefly, between February 2012 and February 2013, study participants were recruited at a community-based health centre for MSM and transgender people, as well as at bars, clubs, volleyball courts, via social media and by snowball sampling. Eligibility criteria for participation were: born anatomically male; at least 18 years old; reported any anal intercourse with a man during the previous 12 months; residing in metropolitan Lima; tested HIV negative at enrolment; willing to commit to twice-yearly clinic visits for 24 months; and had not previously participated in an HIV or HPV vaccine study. HIV status was determined using the Determine HIV-1/2 Combo Ag/Ab test (Alere Medical, Japan) and confirmed by indirect immunofluorescence assay (in-house test, Peruvian National Institute of Health). Enrolled participants were screened for past or active syphilis using the Determine TP test (Alere Medical) and completed a $20 \mathrm{~min}$, computer-assisted self-interview. Participants underwent a physical examination by a study clinician who noted circumcision status and the presence of visible anogenital warts; appropriate treatment and referrals were made as necessary. Using prewetted Dacron swabs, genital specimens were collected from the coronal sulcus/glans penis, penile shaft, scrotum and anus, combined into one sample per participant, stored at $-80^{\circ} \mathrm{C}$, and sent to the Moffitt Cancer Center (USA) for DNA extraction using the QIAamp Media MDx Kit (Qiagen, Germantown, MD) followed by PCR and HPV genotyping. The samples were combined in this way to increase cost-effectiveness of the HPV genotyping. The Linear Array Assay (Roche Diagnostics, Indianapolis, IN) was used for detection of $37 \mathrm{HPV}$ genotypes classified as high risk (oncogenic; HPV 16, 18, 31, 33, 35, 39, 45, 51, $52,56,58,59$ and 68 ) or low risk (non-oncogenic; HPV 6 , $11,26,40,42,53,54,55,61,62,64,66,67,69,70,71,72$, 73, 81, 82, 82 subtype IS39, 83, 84 and 89).

Participants were provided approximately US $\$ 3$ for transportation to and from the study site as well as condoms, lubricant and a small gift (eg, water bottle, keychain). All participants provided informed consent before study participation.

\section{Measures}

Data collected in the self-administered survey included: age (years); education level (at least secondary or higher than secondary); sexual identity (homosexual or gay; bisexual; heterosexual; transgender; other); sexual role during anal intercourse with men (ie, activo, pasivo, 
moderno); transactional sex (ie, exchange of money/items of value for sex, ever, yes/no); sex and concomitant drug and alcohol use (past month, yes/no); cigarette use (ever, yes/no); age at first anal intercourse (years); oral sex (given) with a man (ever, yes/no); condom use during anal intercourse (last, yes/no); HPV knowledge ('Have you ever heard of HPV or human papilloma virus prior to participating in this study?', yes/no).

\section{Data analysis}

Beginning with bivariate analysis, we examined all variables only among heterosexually identified and homosexually identified MSM, after which $\chi^{2}$ tests were conducted to compare the frequency of each variable for both groups. Next, using a generalised linear model, we examined the adjusted association of the biological HPV-related variables (ie, anogenital HPV prevalence, anal and penile wart presence and high-risk HPV prevalence) with select sample characteristics, including sexual identity. Only those variables that were statistically significant in the bivariate analysis were included in the models. All analyses were conducted using Stata V.12.0 (StataCorp, College Station, TX).

\section{RESULTS}

Of 756 subjects screened, 600 were determined to be HIV negative by rapid test and enrolled into the main study, of which $48 \%$ (284) identified as homosexual and $10 \%$ (57) as heterosexual.

The mean participant age was 26.91 years (range 18-42, SD 6.07). Table 1 compares frequencies for all variables by group. At baseline, compared with homosexually identified MSM, heterosexually identified MSM were less likely to have: a greater than high school education $(35.09 \%$ vs $66.55 \%, \mathrm{p}=0.000$ ); ever given oral sex to another man ( $47.37 \%$ vs $93.66 \%, \mathrm{p}=0.000)$; used a condom with their most recent female sexual partner $(39.13 \%$ vs $65.91 \%$, $\mathrm{p}=0.036)$; anal warts $(30.00 \%$ vs $68.10 \%$ among those with visible genital warts, $\mathrm{p}=0.001$ ); and have anogenital HPV DNA detected ( $78.95 \%$ vs $89.08 \%, \mathrm{p}=0.035)$. Conversely, heterosexually identified MSM were more likely to: identify as activo ( $71.43 \%$ vs $24.03 \%$, $\mathrm{p}=0.000)$; have both male and female partners $(31.15 \%$ vs $2.69 \%, \mathrm{p}<0.000)$; report transactional sex $(17.54 \%$ vs $5.28 \%, \mathrm{p}<0.001)$; have used drugs during sex in the past month $(15.79 \%$ vs $3.89 \%$, $\mathrm{p}<0.000)$; ever smoke cigarettes $(92.98 \%$ vs $78.29 \%$, $\mathrm{p}<0.010$ ); have used a condom during last anal sex with a man $(56.14 \%$ vs $23.94 \%, \mathrm{p}=0.000)$; and have penile warts $(65.00 \%$ vs $19.83 \%$ among those with visible genital warts, $\mathrm{p}<0.000)$. There was no difference between the groups in HPV knowledge, syphilis or high-risk HPV type prevalence.

In multivariate analysis, none of the biological HPV variables were found to have an independent association with sexual identity.

\section{DISCUSSION}

Heterosexually identified MSM differed significantly from homosexually identified MSM in a variety of ways related to HPV as well as HIV risk and were more likely to report behaviours congruent with behaviourally heterosexual men including having sex with women and being less likely to have had (given) oral sex with another man. Additionally, the heterosexual men in this study were more likely to self-identify as activo, again in line with what would be expected from behaviourally heterosexual MSM following traditional Latino gender norms. However, an activo self-identification was not unanimous for heterosexually identified MSM in this study, with $14 \%$ identifying as pasivo (receptive) during anal intercourse with other men. While it is uncertain how these men conceptualise a heterosexual identification with a pasivo role when having sex with men, it does not necessarily mean that they are 'secretly homosexual or bisexual.' Rather, it may be that these men, like the participants in Carrillo and Hoffman's recent qualitative study of 100 heterosexual-identifying MSM in the USA, firmly identify with a heterosexual identity, do not wish to be seen otherwise and do not see their self-identities changing; it may be that they see themselves as 'heteroflexible' with 'elastic sexualities'. ${ }^{27}$ Of note, Carrillo's study sample was not limited to Latinos but included other races (ie, White, African American, Native American, Asian American and Middle Eastern/ White) which may extend the relevance of the present study beyond heterosexually identified Peruvian MSM.

While the presence of anogenital HPV was detected in fewer heterosexually identified MSM $(78.95 \%)$ compared with homosexually identified MSM $(89.08 \%)$, it was still markedly higher than for heterosexual men who have sex only with women $\left(\leq 50 \%^{16}\right)$ and comparable to previous reports of anogenital HPV DNA prevalence among HIV-negative Peruvian MSM. ${ }^{24}$ Men (in general) who strongly endorse traditional masculine stereotypesperhaps a view shared by the heterosexual MSM in this study-are less likely to receive preventive healthcare services compared with men with more moderate masculinity beliefs. ${ }^{28}$ Moreover, when care is accessed, lower education coupled with high HPV prevalence may increase heterosexually identified MSM's risk for HIV and HPV-associated anogenital cancers because they may not know to ask doctors about HPV, HPV vaccination or HPV-related cancers. Similarly, doctors may not consider them at risk for HPV, and therefore not provide HPV information or vaccine information. ${ }^{21}$ Together with potentially stigmatising experiences when accessing medical attention for genital warts, ${ }^{22}$ the result is a potential missed opportunity for education through physician contact.

Though we do not know the HPV infection route for the heterosexual men with penile warts in our study, they or their treating physicians could assume exposure was via sex with women, thereby avoiding both the embarrassment and shame of being labelled homosexual but circumventing an important point of contact where additional HPV screening and treatment (eg, for anal warts) or HIV or other STI testing could occur. Notably, though penile warts were predominant among the 
Table 1 Characteristics of heterosexually identified $(n=57)$ compared with homosexually identified $(n=284)$ Peruvian men who have sex with men

\begin{tabular}{|c|c|c|c|}
\hline \multirow[b]{2}{*}{ Characteristic } & \multicolumn{2}{|c|}{ Sexual identity } & \multirow[b]{2}{*}{$\chi^{2} \mathrm{p}$ Value } \\
\hline & $\begin{array}{l}\text { Heterosexual } \\
\text { n }(\%)^{*}\end{array}$ & $\begin{array}{l}\text { Homosexual } \\
\mathrm{n}(\%)^{*}\end{array}$ & \\
\hline \multicolumn{4}{|l|}{ Age (years) } \\
\hline $18-20$ & 15/57 (26.32) & $52 / 284(18.31)$ & 0.252 \\
\hline $21-24$ & 19/57 (33.33) & $77 / 284(27.11)$ & \\
\hline 25-32 & $16 / 57(28.07)$ & 104/284 (36.62) & \\
\hline$>32$ & $7 / 57(12.28)$ & $51 / 284(17.96)$ & \\
\hline \multicolumn{4}{|l|}{ Education } \\
\hline At least secondary & $37 / 57(64.91)$ & 95/284 (33.45) & 0.000 \\
\hline Higher than secondary & $20 / 57$ (35.09) & 189/284 (66.55) & \\
\hline \multicolumn{4}{|c|}{ Sex role during anal intercourse with men } \\
\hline Activo & $40 / 56(71.43)$ & 68/283 (24.03) & 0.000 \\
\hline Moderno & $8 / 56(14.29)$ & $91 / 283(32.16)$ & \\
\hline Pasivo & $8 / 56(14.29)$ & 124/283 (43.82) & \\
\hline \multicolumn{4}{|c|}{ Sex of sex partners (previous 6 months) } \\
\hline Male only & $25 / 41(60.98)$ & 217/223 (97.31) & 0.000 \\
\hline Male and female & $14 / 41(31.15)$ & 6/223 (2.69) & \\
\hline Female only & $2 / 41(4.88)$ & 0/223 (0) & \\
\hline \multicolumn{4}{|l|}{ Transactional sex (ever) } \\
\hline Yes & 10/57 (17.54) & 15/284 (5.28) & 0.001 \\
\hline No & $47 / 57(82.46)$ & 269/284 (94.72) & \\
\hline \multicolumn{4}{|c|}{ Drug† use during any sex (past month) } \\
\hline Yes & 9/57 (15.79) & $11 / 283(3.89)$ & 0.000 \\
\hline No & $48 / 57(84.21)$ & 272/283 (96.11) & \\
\hline \multicolumn{4}{|c|}{ Alcohol use during any sex (past month) } \\
\hline Yes & $21 / 57(36.84)$ & $77 / 278(27.70)$ & 0.166 \\
\hline No & $36 / 57(63.16)$ & $201 / 278(72.30)$ & \\
\hline \multicolumn{4}{|l|}{ Cigarette use (ever) } \\
\hline Yes & $53 / 57(92.98)$ & 220/281 (78.29) & 0.010 \\
\hline No & $4 / 57(7.02)$ & $61 / 281(21.71)$ & \\
\hline \multicolumn{4}{|c|}{ Age at first anal intercourse (years) } \\
\hline$<14$ & $8 / 57(14.04)$ & 46/284 (16.20) & 0.865 \\
\hline $14-19$ & $34 / 57(59.65)$ & $171 / 284(60.21)$ & \\
\hline$>19$ & $1557(26.32)$ & 67/284 (23.59) & \\
\hline \multicolumn{4}{|c|}{ Oral sex (giving) to a man (ever) } \\
\hline Yes & $27 / 57(47.37)$ & 266/284 (93.66) & 0.000 \\
\hline No & $30 / 57(52.63)$ & $18 / 284(6.34)$ & \\
\hline \multicolumn{4}{|c|}{ Condom during anal intercourse with man (last) } \\
\hline Yes & $32 / 57(56.14)$ & $68 / 284(23.94)$ & 0.000 \\
\hline No & $25 / 57(43.86)$ & $216 / 284(76.06)$ & \\
\hline \multicolumn{4}{|c|}{ Condom during any intercourse with woman (last) } \\
\hline Yes & 9/23 (39.13) & 29/44 (65.91) & 0.036 \\
\hline No & $14 / 23(60.87)$ & $15 / 44(34.09)$ & \\
\hline
\end{tabular}

Continued 
Table 1 Continued

\begin{tabular}{|c|c|c|c|}
\hline Characteristic & $\begin{array}{l}\text { Heterosexual } \\
\text { n }(\%)^{*}\end{array}$ & $\begin{array}{l}\text { Homosexual } \\
\text { n }(\%)^{*}\end{array}$ & $\chi^{2} \mathrm{p}$ Value \\
\hline Yes & $2 / 57(3.51)$ & $17 / 284(5.99)$ & 0.457 \\
\hline No & $55 / 57(96.49)$ & $267 / 284(94.01)$ & \\
\hline \multicolumn{4}{|l|}{ Syphilis (rapid test) } \\
\hline Positive & $14 / 57(24.56)$ & 47/284 (16.55) & 0.150 \\
\hline Negative & $43 / 57(75.44)$ & $237 / 284(83.45)$ & \\
\hline \multicolumn{4}{|c|}{ Had ever heard of HPV (prior to study) } \\
\hline Yes & $21 / 57(36.98)$ & $146 / 281(51.96)$ & 0.097 \\
\hline No & $36 / 57(63.16)$ & $135 / 281(48.04)$ & \\
\hline \multicolumn{4}{|c|}{ Anogenital (pooled sample) HPV DNA detected } \\
\hline Yes & $45 / 57(78.95)$ & 253/284 (89.08) & 0.035 \\
\hline No & $12 / 57(21.05)$ & $31 / 284(10.92)$ & \\
\hline \multicolumn{4}{|c|}{ Anogenital warts (ever) } \\
\hline Yes & $30 / 57(52.63)$ & $166 / 284(58.45)$ & 0.417 \\
\hline No & $27 / 57(47.37)$ & $118 / 284(41.55)$ & \\
\hline \multicolumn{4}{|l|}{ Genital wart location } \\
\hline Anal & $6 / 20(30.00)$ & $79 / 116(68.10)$ & 0.001 \\
\hline Penile & $13 / 20(65.00)$ & 23/116 (19.83) & 0.000 \\
\hline Anal and penile & $1 / 20(5.00)$ & $9 / 116(7.56)$ & \\
\hline Testes & - & $5 / 116(4.31)$ & \\
\hline \multicolumn{4}{|c|}{ High-risk HPV (pooled anogenital sample) } \\
\hline Yes & 28/57 (49.12) & $153 / 284(53.87)$ & 0.512 \\
\hline No & 29/57 (50.88) & $131 / 284(46.13)$ & \\
\hline
\end{tabular}

Bold font indicates statistical significance at $p<0.05$.

*Because of missing data, not all variables sum to the total $\mathrm{N}$.

†Drugs included: cocaine or its derivative (coca básica), marijuana, poppers.

HPV, human papillomavirus.

heterosexually identified MSM in this study, among those with visible anogenital warts, approximately $30 \%$ had anal warts which could have been missed in a medical screening where exclusive vaginal sex with women, and not the potential for receptive anal sex with men, may have been assumed. Nearly half of the heterosexually identified MSM had a detectable high-risk (ie, oncogenic) HPV genotype detected in their pooled anogenital sample, a reminder that both groups of men could have, and possibly still would, benefit from HPV vaccination.

Important behaviours that could increase HIV/STI transmission risks among heterosexually identified MSM in this study included: drug use during last anal intercourse, having had transactional sex and no condom use during sex with their most recent female partner. While a deeper analysis of these variables was beyond the scope of our primary interest in HPV, we hope to stimulate the inclusion of sexual identity as an independent variable in future HIV/STI research among Latino MSM.

This study is limited by the nature of non-random sampling and cross-sectional design, which confines the findings to associations rather than causality, and our findings cannot be generalised to all Peruvian MSM or all Latino MSM. For clarity, we opted to restrict our analyses to MSM identifying as only exclusively heterosexual or exclusively homosexual. This limited the number of our comparison groups, especially the heterosexual group. Further, the present analyses were restrained by the inherent limitations of performing secondary analyses on data sets with differing primary scientific aims. Larger, prospective, longitudinal studies specific to sexual identity and HIV/STI risks could address these methodological limitations.

This is the first study, to our knowledge, to compare only heterosexually and homosexually identified Latino MSM with regard to HPV and other HIV risk factors. Though narrow in scope, this study adds to a growing body of literature illuminating the diversity of Latino men grouped under the MSM umbrella term. Unlike nearly all other STIs, a preventive vaccine exists for HPV. Though universal, gender neutral HIV vaccination would be ideal, we present further evidence that at least Peruvian MSM 
should be offered access to biomedical interventions that can prevent genital warts and associated cancers. Our study demonstrates that some HPV-related factors may differ between heterosexually identified and homosexually identified MSM which may require tailored, HPV-specific interventions.

Acknowledgements We are grateful to the men and women who participated in this study as well as the staff at the community centre Epicentro in Lima, Peru, where the study was conducted. We thank Jo Gerrard for editorial assistance.

Contributors JTG and BJB designed and led the study, analysed the data and wrote the first draft of the paper. SL and GC managed all laboratory aspects. GC additionally collected clinical specimens. JZ and HS implemented the study, including screening, enrolment, informed consent and data collection. JP performed the statistical analyses. All authors read and contributed to the final version of the manuscript.

Funding This work was supported in part by a research grant from the Merck Investigator- Initiated Studies Program of Merck \& Co., Inc., NIH grant T32 MH080634 and the NIH Health Disparities Research Loan Repayment Program. The opinions expressed in this paper are those of the authors and do not necessarily represent those of Merck \& Co, Inc.

Competing interests None declared.

Ethics approval Institutional Review Boards at the University of California, Los Angeles, USA (approval number: 11-003060) and the Asociación Civil Impacta Salud y Educación in Lima, Perú (approval number: 00183-2011) reviewed and approved all study procedures and documents prior to implementation.

Provenance and peer review Not commissioned; externally peer reviewed.

Data sharing statement № additional unpublished data are available.

Open Access This is an Open Access article distributed in accordance with the Creative Commons Attribution Non Commercial (CC BY-NC 4.0) license, which permits others to distribute, remix, adapt, build upon this work non-commercially, and license their derivative works on different terms, provided the original work is properly cited and the use is non-commercial. See: http://creativecommons.org/ licenses/by-nc/4.0/

(C) Article author(s) (or their employer(s) unless otherwise stated in the text of the article) 2017. All rights reserved. No commercial use is permitted unless otherwise expressly granted.

\section{REFERENCES}

1. Izazola-Licea JA, Valdespino-Gomez JL, Gortmaker SL, et al. HIV-1 seropositivity and behavioral and sociological risks among homosexual and bisexual men in six Mexican cities. J Acquir Immune Defic Syndr 1991;4:614-22.

2. Goodreau SM, Goicochea LP, Sanchez J. Sexual role and transmission of HIV type 1 among men who have sex with men, in Peru. J Infect Dis 2005;191(Suppl 1):S147-58.

3. Goodreau SM, Peinado J, Goicochea P, et al. Role versatility among men who have sex with men in urban Peru. J Sex Res 2007;44:233-9.

4. McLean SA, Galea JT, Prudden HJ, et al. Association between sexual role and HIV status among Peruvian men who have sex with men seeking an HIV test: a cross-sectional analysis. Int J STD AIDS 2016:27:783-9.

5. Clark J, Salvatierra J, Segura E, et al. Moderno love: sexual rolebased identities and HIV/STI prevention among men who have sex with men in Lima, Peru. AIDS Behav 2013;17:1313-28.

6. Zellner JA, Martínez-Donate AP, Sañudo F, et al. The interaction of sexual identity with sexual behavior and its influence on HIV risk among latino men: results of a community survey in northern San Diego County, California. Am J Public Health 2009;99:125-32.

7. Carrier JM. Participants in urban Mexican male homosexual encounters. Arch Sex Behav 1971;1:279-91.

8. Carrier JM. Cultural factors affecting urban Mexican male homosexual behavior. Arch Sex Behav 1976;5:103-24.

9. Stamm WE, Handsfield $\mathrm{HH}$, Rompalo AM, et al. The association between genital ulcer disease and acquisition of HIV infection in homosexual men. JAMA 1988;260:1429-33.

10. Celum $\mathrm{C}$, Wald A, Hughes J, et al. Effect of aciclovir on HIV-1 acquisition in herpes simplex virus 2 seropositive women and men who have sex with men: a randomised, double-blind, placebocontrolled trial. Lancet 2008;371:2109-19.

11. Sanchez J, Lama JR, Kusunoki L, et al. HIV-1, sexually transmitted infections, and sexual behavior trends among men who have sex with men in Lima, Peru. J Acquir Immune Defic Syndr 2007;44:578-85.

12. Sanchez J, Lama JR, Peinado J, et al. High HIV and ulcerative sexually transmitted infection incidence estimates among men who have sex with men in Peru: awaiting for an effective preventive intervention. J Acquir Immune Defic Syndr 2009;51 (Suppl 1):S47-51.

13. Jin F, Prestage GP, Imrie J, et al. Anal sexually transmitted infections and risk of HIV infection in homosexual men. J Acquir Immune Defic Syndr 2010;53:144-9.

14. Owsianka B, Gańczak M. Evaluation of human papilloma virus (HPV) vaccination strategies and vaccination coverage in adolescent girls worldwide. Przegl Epidemiol 2015;69:151-5.

15. Palefsky JM, Rubin M. The epidemiology of anal human papillomavirus and related neoplasia. Obstet Gynecol Clin North Am 2009;36:187-200.

16. Dunne EF, Nielson CM, Stone KM, et al. Prevalence of HPV infection among men: A systematic review of the literature. $J$ Infect Dis 2006;194:1044-57

17. Palefsky JM, Holly EA, Ralston ML, et al. Prevalence and risk factors for human papillomavirus infection of the anal canal in human immunodeficiency virus (HIV)-positive and HIV-negative homosexual men. J Infect Dis 1998;177:361-7.

18. Cummings T, Kasting ML, Rosenberger JG, et al. Catching up or missing out? Human papillomavirus vaccine acceptability among 18 to 26-year-old men who have sex with men in a US national sample. Sex Transm Dis 2015;42:601-6.

19. Gerend MA, Madkins K, Phillips G, et al. Predictors of human papillomavirus vaccination among young men who have sex with men. Sex Transm Dis 2016;43:185-91.

20. Cáceres CF, Aggleton P, Galea JT. Sexual diversity, social inclusion and HIV/AIDS. AIDS 2008;22(Suppl 2):S35-43.

21. Knight DA, Jarrett $D$. Preventive health care for men who have sex with men. Am Fam Physician 2015;91:844-51.

22. Nureña CR, Brown B, Galea JT, et al. HPV and genital warts among Peruvian men who have sex with men and transgender people: knowledge, attitudes and treatment experiences. PLoS One 2013;8:e58684

23. Ministerio de Salud del Perú (Peruvian Ministry of Health). Norma técnica de salud que establece el esquema nacional de vacunación (Technical standards establishing the national vaccination program). Lima, Perú: Ministerial Resolution, 2013.

24. Quinn R, Salvatierra J, Solari V, et al. Human papillomavirus infection in men who have sex with men in Lima, Peru. AIDS Res Hum Retroviruses 2012;28:1734-8.

25. Blas MM, Brown B, Menacho L, et al. HPV prevalence in multiple anatomical sites among men who have sex with men in peru. PLoS One 2015;10:e0139524

26. Brown B, Davtyan M, Leon SR, et al. A prospective cohort study characterising the role of anogenital warts in HIV acquisition among men who have sex with men: a study protocol. BMJ Open 2014;4:e005687.

27. Carrillo H, Hoffman A. From MSM to heteroflexibilities: Non-exclusive straight male identities and their implications for HIV prevention and health promotion. Glob Public Health 2016;11:923-36.

28. Springer KW, Mouzon DM. "Macho men" and preventive health care: implications for older men in different social classes. $J$ Health Soc Behav 2011;52:212-27. 